\title{
A test method for the determination of the peel resistance of the bonded rubber lining of conveyor belt metal drums
}

\author{
Sofia Papanikolaou ${ }^{1, *}$, Andreas Maropoulos ${ }^{1}$, Dimitrios Fasnakis $^{1}$, Stergios Maropoulos ${ }^{1}$ \\ ${ }^{1}$ Department of Mechanical Engineering and Industrial Design, University of Applied Sciences of \\ West Macedonia, Kozani, Greece.
}

\begin{abstract}
A test method for the peel resistance of the bonded rubber lining of large of large conveyor belt metal drums is presented that will assist engineer in designing conveyor systems with predetermined specifications. A simple specimen preparation method is developed and the peel strength of the liming is measured using a modified version of the Standard EN 28510-1:2014, 'Adhesives-Peel test for a flexible-bonded-to-rigid test specimen assembly' [1]. The method was applied to various types of samples and it was found that only metal drums where the rubber lining was bonded using hot-vulcanisation under pressure satisfied the condition of the peel force greater than $2 \mathrm{~N} / \mathrm{m}$.
\end{abstract}

\section{Introduction}

The lignite ore from the mines is transported to the power stations by large scale belt conveyor systems. The motion of the belt conveyor system is controlled by a driving station, which consists mainly of two driving pulleys or drums and one pre-tensioning pulley $[2,3]$. The pulley drums are thin walled structures produced by rolling a $6-25 \mathrm{~mm}$ thick St37, St44, St52 steel sheet and welding it with two end plates. The final drum dimensions are $\mathrm{L}=550-1400 \mathrm{~mm}, \mathrm{D}=190-1000 \mathrm{~mm}$. In order to avoid "slipping" between belt and pulley, rubber lining or "lagging" is glued onto drive pulleys using either a hot or cold bonding process. The lagging increases the friction coefficient and at the same time, wetness and dirt are repelled, which secures a safe performance of the belt conveyor [4]. In addition, drum lagging can reduce belt tensions and, therefore, a lower belt rating may be possible. Drum lagging is usually applied by a process including hot vulcanizing [5]. The significant advantage of this process compared to cold drum lagging is the higher adhesion values received. The process involves a number of steps. The metal surface is machined to the required roughness usually $\mathrm{Ra}=2 \mathrm{~mm}, \mathrm{Rz}=0.4 \mathrm{~mm}$ and after it has been thoroughly cleaned it is heated to $50 \mathrm{oC}$ and a $5-10 \mu$ primer is applied. The primer is a thermally activated adhesive designed for use as the substrate under other bonding agents. It consists of a mixture of polymers, organic compounds and inorganic fillers dissolved or dispersed in an organic solvent system. Then $10-20 \mu$ of glue is applied. The glue is made of an

*Corresponding author: sofiapapan@gmail.com 
elastomeric adhesive and is a lead-free coating material designed for use with a primer. This bonding system is used for bonding to a variety of elastomeric compounds with metal and plastic substrates during the vulcanization process.

The appropriate rubber is chosen from a variety of materials such as rubber with ethylene and propylene, rubber containing butyl, natural rubber, styrene-butadiene rubbers, rubber containing silicone and natural rubber, nitrile rubber and polyurethane rubber. A 2 to $5 \mathrm{~mm}$ rubber sheet is placed on a heated surface to soften before putting it on the drum. Two layers of such rubber sheets are wrapped around the drum and the drum is then placed in a furnace for 12 hours at $140{ }^{\circ} \mathrm{C}$ at a pressure of 5 bars.

Frequent break downs are observed in the conveyor belt system [6] mainly due to the sudden ungluing of large pieces of rubber lining from the metal drum surface resulting in lining rupture, conveyor belt tearing and even conveyor motors breaking down. The absence of rules for the certification of metal drums by European legislation made it imperative to establish a private certification standard whereby the peel resistance of the bonded rubber lining can be tested prior to installation. The present case study developed the test standard, which is a modification of the standard EN 28510.01, by which the Greek Public Power Corporation (PPC) tests conveyor belt drums for all its power plants. A detailed investigation of various types of drum lining peel resistance is presented which revealed that drum lagging applied by a process including hot vulcanizing exhibited higher peel force values compared to the cold bonding process using rubber based glue.

\section{Methods}

\subsection{Specimen preparation}

Two types of specimens were prepared to be tested for rubber to metal peel resistance.

a) A number of flat and curved specimens, Figure 1, were prepared having the same steel and rubber material as those of actual drums and using the same rubber to metal bonding hot vulcanizing process but having half the length of the rubber free (not glued to the metal) by placing a strip of aluminium foil on half the metal surface during bonding. This resulted in a sharp adhesive boundary from which rubber separation will commence during the peel test. Another set of specimens were prepared by a cold bonding process using rubber based glue $[7,8]$.

b) A number of curved test specimens, Figure 1, $400 \mathrm{~L} \mathrm{~mm} \mathrm{x} 100 \mathrm{~W} \mathrm{~mm}$, were precision laser cut from actual conveyor drums belonging to the Greek Public Power Corporation (PPC SA) power plants as shown in Figure 1(b). Half the length of the rubber lining was unglued to be held by the top flat machine grip, Figure 2 .

(a)
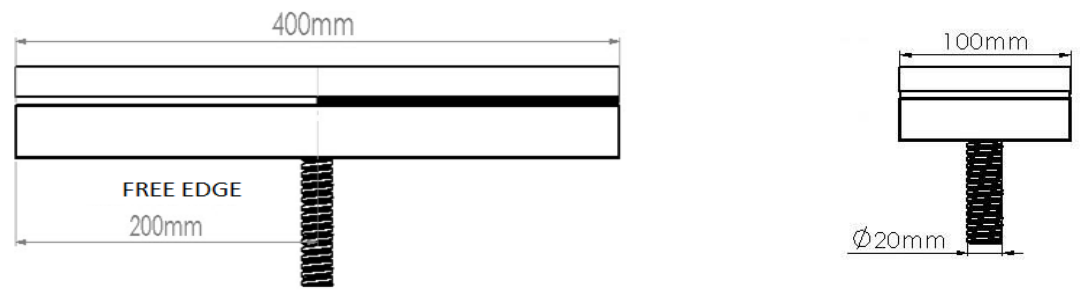
(b)
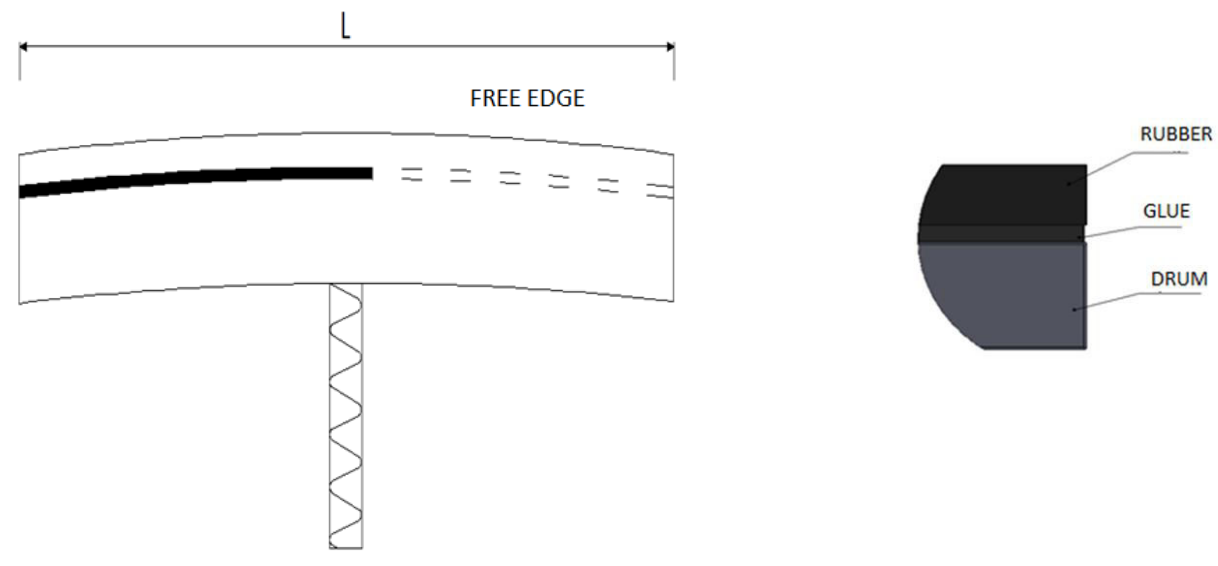

Fig. 1. a) Flat specimens b) Curved specimens cut from real drums

A $140 \mathrm{~mm}$ long, $20 \mathrm{~mm}$ diameter bolt was then screwed to the metal side of the specimens, to be held by the tensile testing machine bottom round grip, Figure 2.
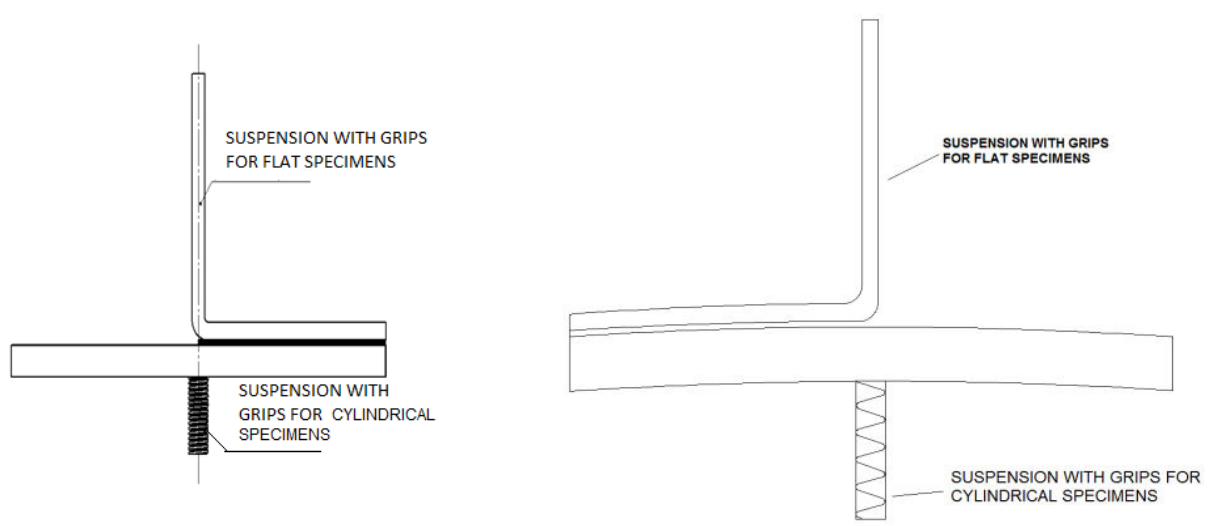

Fig 2. Curved specimens clamped by tensile testing machine flat (top) and round (bottom) grips.

\subsection{Peel Test}

The "Centre for Testing Materials and Constructions" (CTMC), Department of Mechanical Engineering and Industrial Design, TEI West. Macedonia in co-operation with the engineers of PPC SA, realizing the need and significant gap that exists today in the 
international market for the certification of the rubber lining of the conveyor belt metal drums, created a private certification standard "Rubber Drum Peel Test" (RDPT). The (RDPT) standard is essentially a modification of EN 28510.01 "Adhesives-Peel test for a flexible-bonded-to-rigid test specimen assembly-Part 1: $90^{\circ}$ peel" [1] where the test piece dimensions are adjusted from L150mm x W25mm to L400mm x W100mm to meet the dimensions and materials of the conveyor metal drums. The flexible rubber lining is bent through an angle of $90^{\circ}$ and is gripped by the test machine top grip while the rigid metal adherent is gripped by at the bolt screwed in it by the machine bottom grip, Figure 2. A grip separation rate of $50 \mathrm{~mm} / \mathrm{min}$ is used and the force as a function of grip separation is recorded autographically, Figure 3, until a bonded length of $100 \mathrm{~mm}$ from the centre of the test piece has separated, Figure 4.

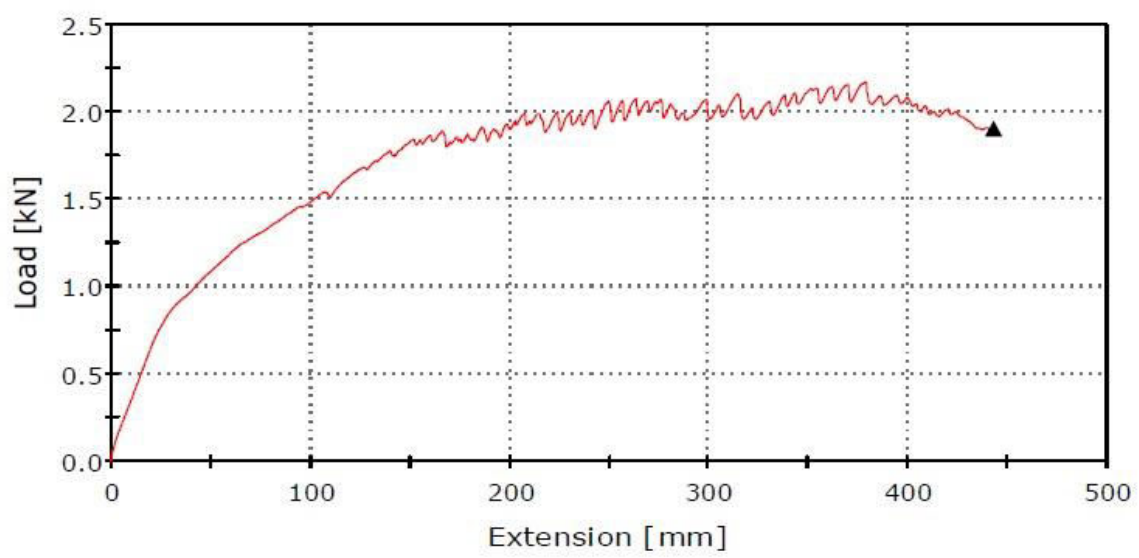

Fig 3. Test force - grip separation diagram

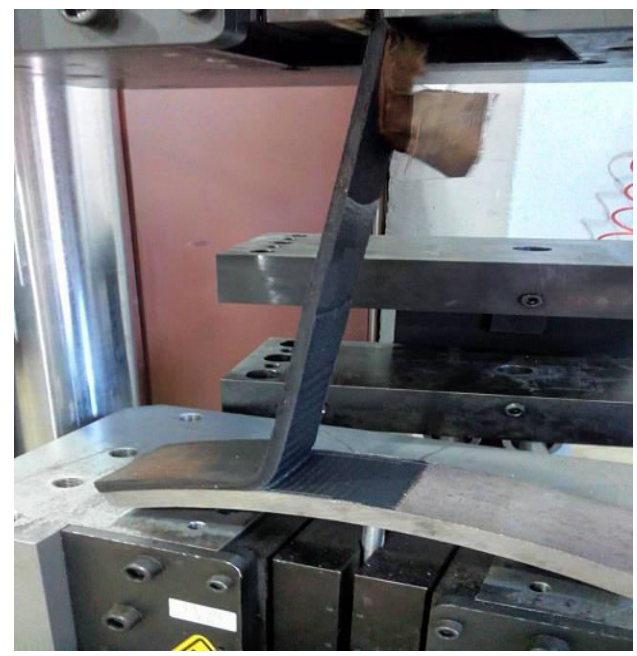

Fig 4. End of peel test, a bonded length of $100 \mathrm{~mm}$ has separated. 


\section{Results and Discussion}

Firstly, a number of specimens were taken from drums that had performed adequately with no problems of rubber lining ungluing after being in operation for at least two years. This was in order to determine the peel strength specification that the private certification standard "Rubber Drum Peel Test" (RDPT) would set. The maximum and minimum peel force obtained from the peel force-peel length curves of the tests as well as the mean peel force obtained from an estimated average line, Figure 3, are shown in Table 1 for all the specimens tested.

Table 1. Peel test results of $100 \mathrm{~mm}$ wide specimens machined from actual conveyor drums.

\begin{tabular}{|c|c|c|c|c|}
\hline specimen & $\mathrm{F}_{\max }(\mathrm{kN})$ & $\begin{array}{l}\text { Extension } \\
\text { at } \mathrm{F}_{\max }(\mathrm{mm})\end{array}$ & $\mathrm{F}_{\min }(\mathrm{kN})$ & $\mathrm{F}_{\text {mean }}(\mathrm{kN})$ \\
\hline 1 & 2.43 & 224.6 & 2 & 2.12 \\
\hline 2 & 2.6 & 370 & 2.3 & 2.4 \\
\hline 3 & 2.5 & 350 & 2.2 & 2.3 \\
\hline 4 & 2.5 & 350 & 2.2 & 2.3 \\
\hline 5 & 2.76 & 209 & 2 & 2.1 \\
\hline 6 & 2.7 & 75.15 & 2.3 & 2.4 \\
\hline 7 & 1.94 & 145.5 & 1.6 & 1.8 \\
\hline 8 & 2 & 300 & 1.5 & 1.8 \\
\hline 9 & 2.4 & 320 & 1.6 & 1.7 \\
\hline 10 & 1.96 & 160 & 1.6 & 1.8 \\
\hline 11 & 2.4 & 310 & 1.6 & 2 \\
\hline 12 & 2.2 & 193 & 1.8 & 2 \\
\hline 13 & 2.17 & 378 & 1.9 & 2. \\
\hline 14 & 2.75 & 180 & 2.4 & 2.6 \\
\hline 15 & 2.43 & 209 & 2.2 & 2.3 \\
\hline 16 & 2 & 200 & 1.7 & 1.8 \\
\hline 17 & 2.5 & 140 & 2 & 2.2 \\
\hline 18 & 2.03 & 227 & 1.5 & 1.7 \\
\hline 19 & 3.3 & 350 & 2.5 & 2.9 \\
\hline 20 & 2.57 & 350 & 2.4 & 2.45 \\
\hline Mean values & 2.40 & 252.06 & 1.86 & 2.16 \\
\hline
\end{tabular}

As can be seen almost all the specimens exhibited $F_{\max }$ values well over $2 \mathrm{kN}$ and $F_{\text {mean }}$ values around $2 \mathrm{kN}$. It was decided that the private standard specification would require a minimum $\mathrm{F}_{\text {mean }}$ value of $2 \mathrm{kN}$ for the specimen to be acceptable. Subsequently, ten flat and six curved specimens, which had been prepared using the same method (hot vulcanizing) as actual drums, were tested in order to determine if they met the $F_{\text {mean }}$ specification of $2 \mathrm{kN}$. The results are shown in Tables 2 and 3 . As can be seen both the $F_{\text {mean }}$ values of the curved and the flat specimens exceeded the $2 \mathrm{kN}$ specification. However, when another set of specimens prepared by a cold bonding process using rubber based glue were tested it was found that they failed to meet the $\mathrm{F}_{\text {mean }}$ specification of $2 \mathrm{kN}$ by approximately $25 \%$ and even the $\mathrm{F}_{\max }$ value was far under $2 \mathrm{kN}$, Table 4 , indicating that cold bonding is not suitable for the needs of the conveyor belt metal drums. 
Table 2. Peel test results of curved specimens made using the same method (hot vulcanizing) as actual drums.

\begin{tabular}{|c|c|c|c|c|}
\hline specimen & $\mathrm{F}_{\max }(\mathrm{kN})$ & $\begin{array}{c}\text { Extension } \\
\text { at } \mathrm{F}_{\max }(\mathrm{mm})\end{array}$ & $\mathrm{F}_{\min }(\mathrm{kN})$ & $\mathrm{F}_{\text {mean }}(\mathrm{kN})$ \\
\hline $\mathrm{B} 1$ & 2.2 & 376.2 & 2.1 & 2.1 \\
\hline B2 & 2,3 & 281.8 & 1.9 & 2.1 \\
\hline B4 & 2.0 & 213.1 & 1.5 & 1.8 \\
\hline B5 & 2.4 & 301.0 & 1.9 & 2.2 \\
\hline B7 & 2.2 & 309.3 & 1.9 & 2.1 \\
\hline B9 & 2.6 & 342.5 & 2.4 & 2.5 \\
\hline Mean values & 2.28 & 304 & 1.95 & 2.13 \\
\hline
\end{tabular}

Table 3. Peel test results of flat specimens made using the same method (hot vulcanizing) as actual

\begin{tabular}{|c|c|c|c|c|}
\hline specimen & $\mathrm{F}_{\max }(\mathrm{kN})$ & $\begin{array}{c}\text { Extension } \\
\text { at } \mathrm{F}_{\max }(\mathrm{mm})\end{array}$ & $\mathrm{F}_{\min }(\mathrm{kN})$ & $\mathrm{F}_{\text {mean }}(\mathrm{kN})$ \\
\hline 1 & 2.26 & 314 & 2 & 2.1 \\
\hline 2 & 2.2 & 367 & 1.9 & 1.95 \\
\hline 3 & 2 & 229 & 1.7 & 1.85 \\
\hline 4 & 2.14 & 318 & 2 & 2.1 \\
\hline 5 & 2 & 317 & 1.7 & 1.85 \\
\hline 6 & 1.99 & 437 & 1.8 & 1.95 \\
\hline 7 & 2.11 & 365 & 2 & 2.1 \\
\hline 8 & 1.9 & 299 & 1.7 & 1.85 \\
\hline 9 & 2.2 & 306 & 1.95 & 2.1 \\
\hline 10 & 2.17 & 308 & 2.05 & 2.1 \\
\hline Mean values & 2.097 & 326 & 1.85 & 2.085 \\
\hline
\end{tabular}

Table 4. Peel test results of curved specimens made a cold bonding process using rubber based glue.

\begin{tabular}{|c|c|c|c|c|}
\hline specimen & $\mathrm{F}_{\max }(\mathrm{kN})$ & $\begin{array}{c}\text { Extension } \\
\text { at } \mathrm{F}_{\max }(\mathrm{mm})\end{array}$ & $\mathrm{F}_{\min }(\mathrm{kN})$ & $\mathrm{F}_{\text {mean }}(\mathrm{kN})$ \\
\hline 1 & 1.8 & 200 & 1.7 & 1.75 \\
\hline 2 & 1.76 & 247 & 1.4 & 1.58 \\
\hline 3 & 1.04 & 123 & 1 & 1.02 \\
\hline 4 & 1.75 & 185 & 1.6 & 1.67 \\
\hline 5 & 1.91 & 188 & 1.5 & 1.7 \\
\hline Mean values & 1.65 & 188.6 & 1.44 & 1.54 \\
\hline
\end{tabular}


The force grip separation curves of the tests shown in Table 2 are exhibited in Figure 5. As can be seen the curves follow the same pattern and this is proof of the reproducibility of the test method used.

It was decided that, as with the EN 28510.01 standard, the private specification would require a set of five specimens to be tested and if they all exceeded the $F_{\text {mean }}$ value of $2 \mathrm{kN} \mathrm{a}$ metal drum with a rubber lining could be declared suitable for service in the Greek Public Power Corporation conveyor belts in all its power plants

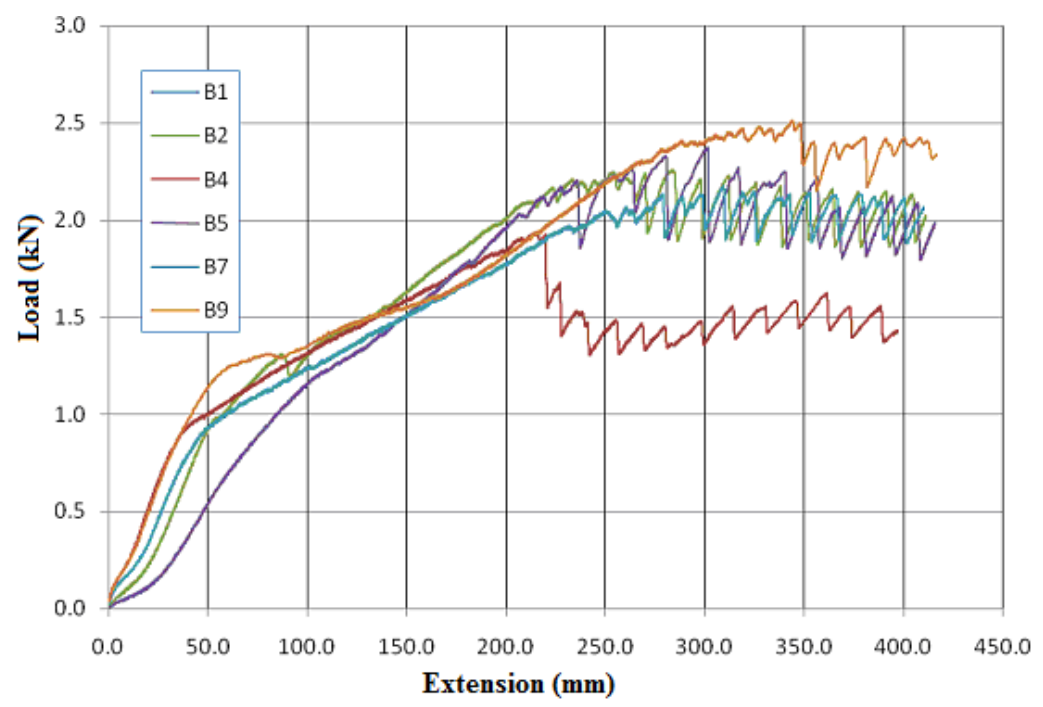

Fig 5. Force grip separation curves of curved specimens made using the same method (hot vulcanizing) as actual drums.

\section{Conclusions}

1. The test method developed offers a simple way of measuring the peel resistance of the bonded rubber lining of metal drums and can be used to estimate drum service performance accurately.

2. The test method developed produces highly reproducible results.

3. Hot vulcanization results in higher bondage of the rubber lining on the metal drum than cold bonding using rubber based glue.

4. A mean separation force of over $2 \mathrm{kN}$ for a $100 \mathrm{~mm}$ wide specimen is to be exhibited for the metal drum rubber lining to be acceptable.

\section{References}

1. EN 28510.01 'Adhesives-Peel test for a flexible-bonded-to-rigid test specimen assembly-Part 1: $90^{\circ}$ peel', (2014).

2. A. Mihailidis, E. Bouras, E. Athanasopoulos, 6th BETA CAE International Conference, Thessaloniki, Greece, (10-12 June 2015).

3. D. R. H. Jones, Engineering Failure Analysis, Volume 2, 1995, p.p. 59-69. 
4. Brett DeVries P.E, 'Variant Friction Coefficients of Lagging and Implications for Conveyor Design' https://www.cemanet.org/wp-content/uploads/2015/10/VariantFriction-Coefficients-for-Lagging-and-Implications.pdf.

5. Bryan Crowther, iSmithers Rapra Publishing, p.p. 384, (2001).

6. P. Ormsbee, A. V. Reicks P.E, Annual SME Meeting in Phoenix, Overland Conveyor Company, Inc. Lakewood, CO http://www.elastotec.com.au/blog/drive-pulley-laggingthe-importance-of-proper-technical-analysis-and-selection/ (2010).

7. WJ Van Ooij, Surface Science, Volume 68 (1977).

8. Senthil K. Jayaseelan and W. J. Van Ooij, Journal of Adhesion Science and Technology, 15, Issue 8, p.p. 967-991, (2001). 